\title{
Ecological Risk Assessment (ERA) of pesticides from freshwater ecosystems in the Pampas region of Argentina: Legacy and current use chemicals contribution
}

\author{
Fernando Gastón Iturburu ${ }^{\text {a,* }}$, Gabriela Calderon ${ }^{\text {b }}$, María Valeria Améc, Mirta Luján Menone ${ }^{\text {a }}$

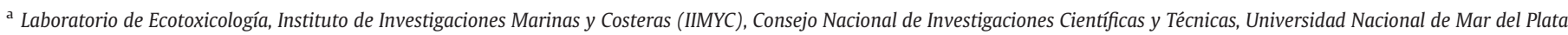 \\ (CONICET- UNMdP), Dean Funes 3350, 7600, Mar del Plata, Buenos Aires, Argentina \\ ${ }^{\mathrm{b}}$ Instituto del Hábitat y del Ambiente, Universidad Nacional de Mar del Plata (UNMdP), Dean Funes 3350, 7600, Mar del Plata, Buenos Aires, Argentina

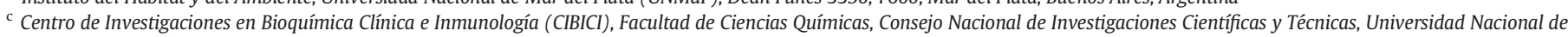 \\ Córdoba (CONICET-UNC), Haya de la Torre esq, Medina Allende, 5000 Córdoba, Argentina
}

\section{H I G H L I G H T S}

- Ecological Risk Assessment was developed both for current use and legacy pesticides.

- In Pampas region, $29 \%$ of reported sites showed high risk for current use pesticides.

- High risk sites increased at $41 \%$ when legacy chemicals were incorporated.

- Compounds banned in Europe but allowed in Argentina highly contribute to risk.

\section{G R A P H I C A L A B S T R A C T}

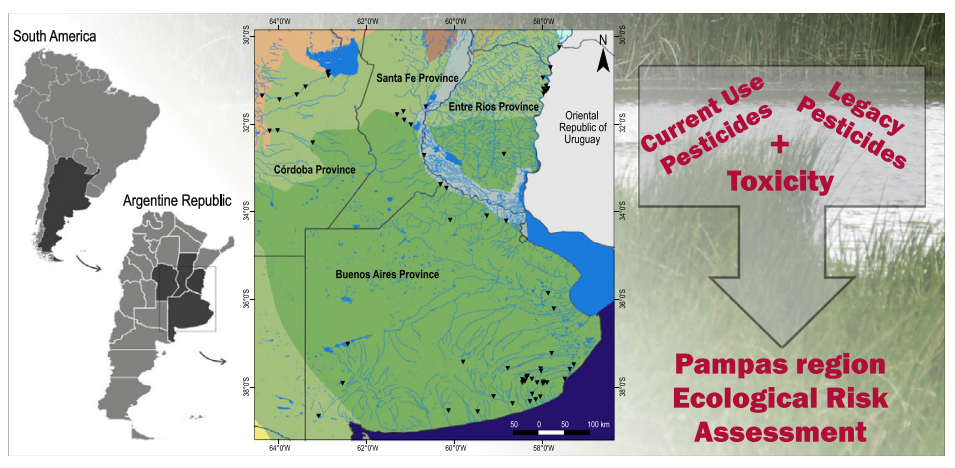

\section{A B S T R A C T}

Agricultural production in the Pampas region is one of the most important economic activities in Argentina. However, the possible environmental effects related to the growth of this activity in the last years have not been studied enough. Particularly, the effects of pesticides mixtures are a topic of great concern both for society and regulatory authorities worldwide, given the possible additive and synergistic relationships between these chemicals and their possible effects on aquatic biota. Based on a concentration addition model, this study developed an Ecological Risk Assessment (ERA) of pesticides from freshwater ecosystems in the Pampas region. For this purpose, reported pesticides concentrations available in public bibliography and a Risk Quotients (RQs) approach were used. A cumulative risk map was established to display RQs for current use pesticides (CUPs) and legacy chemicals. The ERQs were calculated for 66 sites, using available reported measured environmental concentrations (MECs) and predicted no effect concentrations (PNECs) of pesticides. While $\Sigma R Q$ for only CUPs resulted in a high and very high risk ( $\mathrm{R} R$ $>1$ ) for $29 \%$ of the sites, when legacy pesticides were incorporated this percentage reached the $41 \%$ of the sites, increasing significantly the absolute values of $\mathrm{RQ}$. Herbicides like glyphosate and atrazine contributed considerably to the $\Sigma R Q_{c u p s}$ while organochlorines were the major contributors for $\Sigma R Q s$ when legacy pesticides were incorporated. Moreover, some active ingredients (acetochlor, carbendazim and fenitrothion) which are approved for their use in Argentina but banned in EU showed high contribution to $\Sigma R_{\text {cups. }}$. The present study is the first attempt to develop

\footnotetext{
* Corresponding author.

E-mail address: iturburu@mdp.edu.ar (F.G. Iturburu).
} 
an ERA in surface water of the Pampas region of Argentina and it provides a starting point for a more comprehensive pesticides monitoring and a further risk assessment program.

(C) 2019 Elsevier B.V. All rights reserved.

\section{Introduction}

Extensive production of grains and oilseeds (mainly soybean and corn) is the main economic activity of Argentina (Leguizamón, 2014). Most of this production occurs in the Pampas region, one of the largest flatlands in the world, which includes the center-east part of Argentina, as well as most of Uruguay and the southern extreme of Brazil and it is characterized by a temperate but humid climate. This agricultural production was boosted by the introduction of genetically modified organisms in the middle of the 90s decade and it has led to changes in land use, agricultural practices and economy (Arancibia, 2013).

Pesticides are probably the most studied environmental pollutants (Connell, 2005). Pollution by pesticides affects not only soils and biota directly related to crops where these chemicals are applied, but it also produces adverse effects on freshwater ecosystems surrounding croplands and the organisms who live there (Lytle and Lytle, 2001). These substances are included in the group of environmental stressors which are leading to a biodiversity crisis in global surface waters (Liess et al., 2016). Aquatic organisms are often exposed to pesticide mixtures with fluctuating compositions and concentrations (van Gestel et al., 2011). A major concern is that some chemical compounds could modify the effects of other ones on biota, either increasing (synergism) or decreasing the effects of isolated chemicals (antagonism; Cedergreen, 2014). Field studies all around the world show the ubiquity of complex mixtures in water bodies, including studies from northern farmable regions in Europe (Gustavsson et al., 2017) to South America (De Gerónimo et al., 2014), and encompassing from western regions in California (Anderson et al., 2018) to eastern regions in the world (Derbalah et al., 2018).

Mathematical models such as the concentration addition (CA) model are tools capable of predicting toxicity of mixtures which contain pesticides with different mechanisms of action (Altenburger et al., 1996). Particularly, the use of Risk Quotients (RQs) considering Predicted Environmental Concentration/Predicted No Effect Concentration approach (PEC/PNEC) serves as a justifiable CA-approximation, in order to estimate a potential risk for an exposed ecosystem when only few data are available (Backhaus and Faust, 2012). However, calculating this ratio using measured (instead of predicted) concentrations is widely accepted; PNEC may be calculated on the basis of reported critical concentrations $\left(\mathrm{EC}_{50}, \mathrm{LC}_{50}, \mathrm{NOEC}\right)$ taking into account an assessment factor (AF) which includes consideration of data uncertainty (Papadakis et al., 2015). Hence, by employing toxicity data available in bibliographic and public databases like the Pesticides Properties Database (PPDB, Lewis et al., 2016) or the US-EPA ECOTOX database (US-EPA, 2018), it is possible to model expected toxicity of pesticides mixtures quantified in the environment (Deneer, 2000).

Regulations on pesticides' use differ among countries and regions, and Argentina presents clear differences when comparing its legislation with EU countries. For instance, while in Sweden the use of the organochlorine insecticide endosulfan was banned since December 1997 (Swedish Chemicals Agency, 2014) in Argentina the sales of this pesticide were allowed until July 2013 (SENASA, 2011). This big difference among use restriction, and the long persistence of endosulfan and its metabolites in the environment (Bussian et al., 2015), means it is possible to find $\alpha$ and $\beta$ endosulfan as well as endosulfan-sulfate in different matrices of Argentina environment in contemporary surveys (Lupi et al., 2016; Williman et al., 2017). Moreover, the differences in pesticides' use and regulation do not cover only persistent organic pollutants, but also other insecticides (carbamates) as well as fungicides and herbicides, which are approved for its application in Argentina but not in the European Union (EU, for a more complete review see Table 1 in the Supplemental Data 1).

Recently, it was suggested that additional attention should be directed to legacy chemicals' presence in aquatic ecosystems when performing Ecological Risk Assessment (ERA), because neglecting their presence may underestimate predicted toxicity (Rasmussen et al., 2015). Considering this recommendation and the lack of a national monitoring program of pesticides, the present work aims at developing an ERA of pesticides in the Argentine Pampas region. For this purpose, previously reported pesticides concentrations in surface water available to the public and the RQ approach were used. Moreover, to establish a risk map for the Pampas region and to identify the data required for a more comprehensive ERA, both current use pesticides (CUPs) as well as legacy chemicals were taken into account.

\section{Material and methods}

\subsection{Data collection}

Reported Measured Environmental Concentrations (MECs) of both current use and legacy pesticides were obtained from a literature review of original articles available in Science Direct portal (https:// www.sciencedirect.com/). The following criteria were taken into account for articles selection: i) reports of pesticides concentrations in surface water of freshwater ecosystems of the Pampas region of Argentina published in the last 12 years (2007-2018), ii) georeferenced sampling points for reported pesticides concentrations in order to elaborate a risk map, iii) reports of both CUPs and/or legacy pesticides to distinguish the contribution of each group on ERA. Fifteen papers met these criteria (Table 1 ). Only three articles with relevant monitoring data were not included in the assessment (Gonzalez et al., 2012, De Gerónimo et al., 2014, Etchegoyen et al., 2017) because it was not possible to relate reported pesticides concentrations in water with specific coordinates.

Toxicity endpoints were obtained from the PPDB. Fish acute and chronic toxicity ( $96 \mathrm{~h} \mathrm{LC}_{50}$ and 21 days NOEC) in rainbow trout Oncorhynchus mykiss, aquatic invertebrates' acute and chronic toxicity (48 $\mathrm{h} \mathrm{EC}_{50}$ and 21 days NOEC) in water flea Daphnia magna and algal acute and chronic toxicity ( 72 h EC $_{50}$ and 96 h NOEC) in Scenedesmus subspicatus were used as toxicity endpoints.

\subsection{Calculation of RQs}

Environmental risk was assessed based to the RQ approach, which has as assumption a concentration addition effect, where mixture toxicity is conformed for the addition of effects of each isolated pesticide (Bundschuh et al., 2014). RQ was calculated, according to Eq. (1) (Vryzas et al., 2011):

$\mathrm{RQ}=\mathrm{MEC} / \mathrm{PNEC}$

where MEC is the reported measured environmental concentration of a pesticide in water and PNEC is the predicted no effect concentration. Only reports where pesticides concentrations were quantified were 


\section{Table 1}

Reports of pesticides from freshwater ecosystems in the Pampas region used for Ecological Risk Assessment and calculated risk quotients for site. $\Sigma \mathrm{RQ}_{\text {cups }}$ : risk quotients for current use pesticides. $\Sigma \mathrm{RQ}_{\text {total }}$ : risk quotients for all the pesticides reported in each site. LC contribution \%: contribution of legacy chemicals to RQTotal. Geo-localization of each reported site is available in a .kmz file in Supplemental Data 2.

\begin{tabular}{|c|c|c|c|c|c|}
\hline Reference & $\begin{array}{l}\text { Class of } \\
\text { chemicals }\end{array}$ & $\begin{array}{l}\text { Site } \\
\text { ID }\end{array}$ & $\Sigma R_{\text {CUPs }}$ & $\Sigma R Q_{\text {total }}$ & $\begin{array}{l}\text { LC } \\
\text { contribution \% }\end{array}$ \\
\hline \multirow{15}{*}{$\begin{array}{l}\text { Aparicio et al. } \\
\text { (2013) }\end{array}$} & \multirow[t]{15}{*}{ Herbicides } & A01 & 0.0045 & 0.0045 & 0 \\
\hline & & A02 & 0.0025 & 0.0025 & 0 \\
\hline & & A03 & 0.0315 & 0.0315 & 0 \\
\hline & & A04 & 0.0105 & 0.0105 & 0 \\
\hline & & A05 & 0.0040 & 0.0040 & 0 \\
\hline & & A06 & 0.0110 & 0.0110 & 0 \\
\hline & & A07 & 0.0020 & 0.0020 & 0 \\
\hline & & A08 & 0.0105 & 0.0105 & 0 \\
\hline & & A09 & 0.0180 & 0.0180 & 0 \\
\hline & & A10 & 0.0380 & 0.0380 & 0 \\
\hline & & A11 & 0.0105 & 0.0105 & 0 \\
\hline & & A12 & 0.1600 & 0.1600 & 0 \\
\hline & & A13 & 0.0030 & 0.0030 & 0 \\
\hline & & A14 & 0.0030 & 0.0030 & 0 \\
\hline & & A15 & 0.0040 & 0.0040 & 0 \\
\hline \multirow{2}{*}{$\begin{array}{l}\text { Ballesteros } \\
\text { et al. (2014) }\end{array}$} & \multirow{2}{*}{ Insecticides } & B01 & 0 & 22,200 & 100 \\
\hline & & B02 & 0 & 15,700 & 100 \\
\hline \multirow{5}{*}{$\begin{array}{l}\text { Bonansea et al. } \\
\text { (2013) and } \\
(2018)\end{array}$} & \multirow{5}{*}{$\begin{array}{l}\text { Herbicides, } \\
\text { Insecticides }\end{array}$} & $\mathrm{C} 01$ & 41 & 182,641 & 99.98 \\
\hline & & $\mathrm{C} 02$ & 32 & 192,932 & 99.98 \\
\hline & & $\mathrm{C} 03$ & 36 & 428,236 & 99.99 \\
\hline & & $\mathrm{C} 04$ & 38 & 40,238 & 99.90 \\
\hline & & $\mathrm{C} 05$ & 36 & $1,073,436$ & 99.99 \\
\hline \multirow{8}{*}{$\begin{array}{c}\text { Castro-Berman } \\
\text { et al. (2018) }\end{array}$} & \multirow[t]{8}{*}{ Herbicides } & D01 & 0.0045 & 0.0045 & 0 \\
\hline & & D02 & 0.0075 & 0.0075 & 0 \\
\hline & & D03 & 0.0039 & 0.0039 & 0 \\
\hline & & D04 & 0.0081 & 0.0081 & 0 \\
\hline & & D05 & 0.0108 & 0.0108 & 0 \\
\hline & & D06 & 0.0226 & 0.0226 & 0 \\
\hline & & D07 & 0.0082 & 0.0082 & 0 \\
\hline & & D08 & 0.0063 & 0.0063 & 0 \\
\hline \multirow{5}{*}{$\begin{array}{l}\text { Corcoran et al. } \\
\text { (2017) }\end{array}$} & \multirow{5}{*}{$\begin{array}{l}\text { Herbicides, } \\
\text { Fungicides }\end{array}$} & E01 & 0.6631 & 0.6631 & 0 \\
\hline & & E02 & 4.710 & 4.710 & 0 \\
\hline & & E03 & 0.5184 & 0.5184 & 0 \\
\hline & & E04 & 0.3984 & 0.3984 & 0 \\
\hline & & E05 & 0.3318 & 0.3318 & 0 \\
\hline $\begin{array}{l}\text { Lupi et al. } \\
\text { (2016) }\end{array}$ & Herbicides & F01 & 0.0025 & 0.0025 & 0 \\
\hline $\begin{array}{c}\text { Pérez et al. } \\
\text { (2017a) }\end{array}$ & $\begin{array}{c}\text { Herbicides, } \\
\text { Insecticides, } \\
\text { Fungicides }\end{array}$ & G01 & 11.156 & 11.156 & 0 \\
\hline \multirow{7}{*}{$\begin{array}{l}\text { Pérez et al. } \\
\text { (2017b) }\end{array}$} & \multirow[t]{7}{*}{ Herbicides } & H01 & 0.0005 & 0.0005 & 0 \\
\hline & & H02 & 0.0010 & 0.0010 & 0 \\
\hline & & H03 & 0.0010 & 0.0010 & 0 \\
\hline & & H04 & 0.0090 & 0.0090 & 0 \\
\hline & & H05 & 0.0010 & 0.0010 & 0 \\
\hline & & H06 & 0.0040 & 0.0040 & 0 \\
\hline & & H07 & 0.0025 & 0.0025 & 0 \\
\hline \multirow{4}{*}{$\begin{array}{l}\text { Peruzzo et al. } \\
\text { (2008) }\end{array}$} & Herbicides & $\mathrm{I} 01$ & 1.850 & 1.850 & 0 \\
\hline & & I02 & 2.800 & 2.800 & 0 \\
\hline & & I03 & 1.400 & 1.400 & 0 \\
\hline & & I04 & 1.650 & 1.650 & 0 \\
\hline $\begin{array}{l}\text { Primost et al. } \\
\text { (2017) }\end{array}$ & Herbicides & J01 & 0.0063 & 0.0063 & 0 \\
\hline Regaldo et al. & Insecticides & К01 & 0.013 & 50,000 & 100 \\
\hline (2018) & & K02 & 0.0140 & 102,000 & 100 \\
\hline & & K03 & 0.0860 & 130,000 & 99.99 \\
\hline & & K04 & 0.1730 & 130,000 & 99.99 \\
\hline Ronco et al. & Herbicides & L01 & 0.0025 & 0.0025 & 0 \\
\hline (2016) & & L02 & 0.003 & 0.003 & 0 \\
\hline & & L03 & 0.0035 & 0.0035 & 0 \\
\hline $\begin{array}{l}\text { Silva- Barni } \\
\text { et al. (2016) }\end{array}$ & Insecticides & M01 & 0 & 3500 & 100 \\
\hline Williman et al. & Insecticides, & N01 & 96 & 344,467 & 99.97 \\
\hline (2017) & Fungicides & N02 & 0 & 240,827 & 100 \\
\hline & & N03 & 74 & 106,352 & 99.93 \\
\hline & & N04 & 817 & 317,167 & 99.74 \\
\hline & & N05 & 31 & 243,421 & 99.99 \\
\hline & & N06 & 36 & 222,669 & 99.98 \\
\hline & & N07 & 5 & 405 & 98.83 \\
\hline & & N08 & 53 & 48,057 & 99.89 \\
\hline & & N09 & 41 & 778 & 94.79 \\
\hline
\end{tabular}

used for MEC calculation. PNEC was calculated according to Eq. (2):

$\mathrm{PNEC}=\mathrm{CC} / \mathrm{AF}$

where $\mathrm{CC}$ is the critical concentration and $\mathrm{AF}$ is an assessment factor. CCs for water was set as the lowest concentration among no observed effect concentrations (NOECs) for chronic endpoints for fish, aquatic invertebrate and algal species (growth for fish and algae, reproduction for invertebrates). In case of absence of NOEC for all these taxa, the lowest value of $\mathrm{L}(\mathrm{E}) \mathrm{C}_{50}$ was employed. In case of absence of data for previously mentioned species, data of the same group of organisms reported in the PPDB were employed. The NOEC values of parental pesticides were divided by a factor of 10 when toxicity data of metabolites was not available (Altenburger et al., 1996; Vašíčková et al., 2019). AF was established according to Papadakis et al. (2015), being 10 when three NOECs were available, 50 when there were two NOECs available, 100 when there was only one NOEC value (for fish or invertebrate), and 1000 when there was no NOEC values and an $L(E) C_{50}$ was employed.

The $\Sigma R Q_{\text {site }}$ was calculated for each water sampling site, according to Eq. (3):

$\Sigma \mathrm{RQ}_{\text {site }}=\sum_{\mathrm{i}=1}^{\mathrm{n}} R Q_{i}$

where $R Q_{i}$ is the risk quotient for $i$ pesticide. $\Sigma R Q_{\text {site }}>1$ corresponds with possible harmful effects expected (high risk), $\Sigma R Q_{\text {site }}$ between 0.1 and 1 to medium expected risk (medium risk), $\Sigma R Q_{\text {site }}$ between 0.01 and 0.1 correspond to low environmental risk (low risk), while $\Sigma R Q_{\text {site }}<0.01$ shows negligible environmental risk (negligible risk; Sanchez-Bayo et al., 2002). Since several calculated RQs values were markedly greater than unit, a category of $\Sigma R Q_{\text {site }}>10$ was included which corresponds to high probabilities of harmful effects expected (very high risk). Contribution of each pesticide to $\Sigma R Q_{\text {site }}$ according to Eq. (4) (Vašíčková et al., 2019):

contribution $\%=\left(\frac{R Q_{i}}{\Sigma R_{\text {site }}}\right) \times 100$

The same calculations were assessed both for CUPs as well as the sum of CUPs and legacy pesticides, obtaining $\Sigma R Q_{C u P s}$ and $\Sigma R Q_{\text {total }}$, respectively.

\subsection{Cumulative risk maps}

The spatial data of the 66 sampling sites were obtained from the selected research articles. Other spatial data, such as water bodies and streams, were provided by the National Geographic Institute (IGN) and the National Park Administration (APN) of Argentina. Cumulative risk maps are the most common way to model the combination of single stressors in a single parameter (Lahr and Kooistra, 2010), in this case RQs. Resulting maps (for $\Sigma R Q_{C u P s}$ and $\Sigma R Q_{\text {total }}$ ) were elaborated with the GIS software QGIS 2.18.9. All GIS information was projected in WGS-84 reference coordinate system.

\section{Results and discussion}

All the sample points used in this study are within the humid Pampas and Argentine Espinal ecoregions (Administración de Parques Nacionales (APN), 2019, Fig. 1), both included in the Pampas geographical region. Of the 15 geo-referenced reports, $67 \%$ of then showed the presence of at least one herbicide, $40 \%$ showed presence of insecticides and $20 \%$ of fungicides. However, only 4 articles showed the co- occurrence of more than one family of pesticides, while it is worth noting that only one article reported the presence of herbicides, insecticides and fungicides (Table 1). In the period 2007-2018, seven active ingredients approved for use in Argentina but not in the EU were reported, 


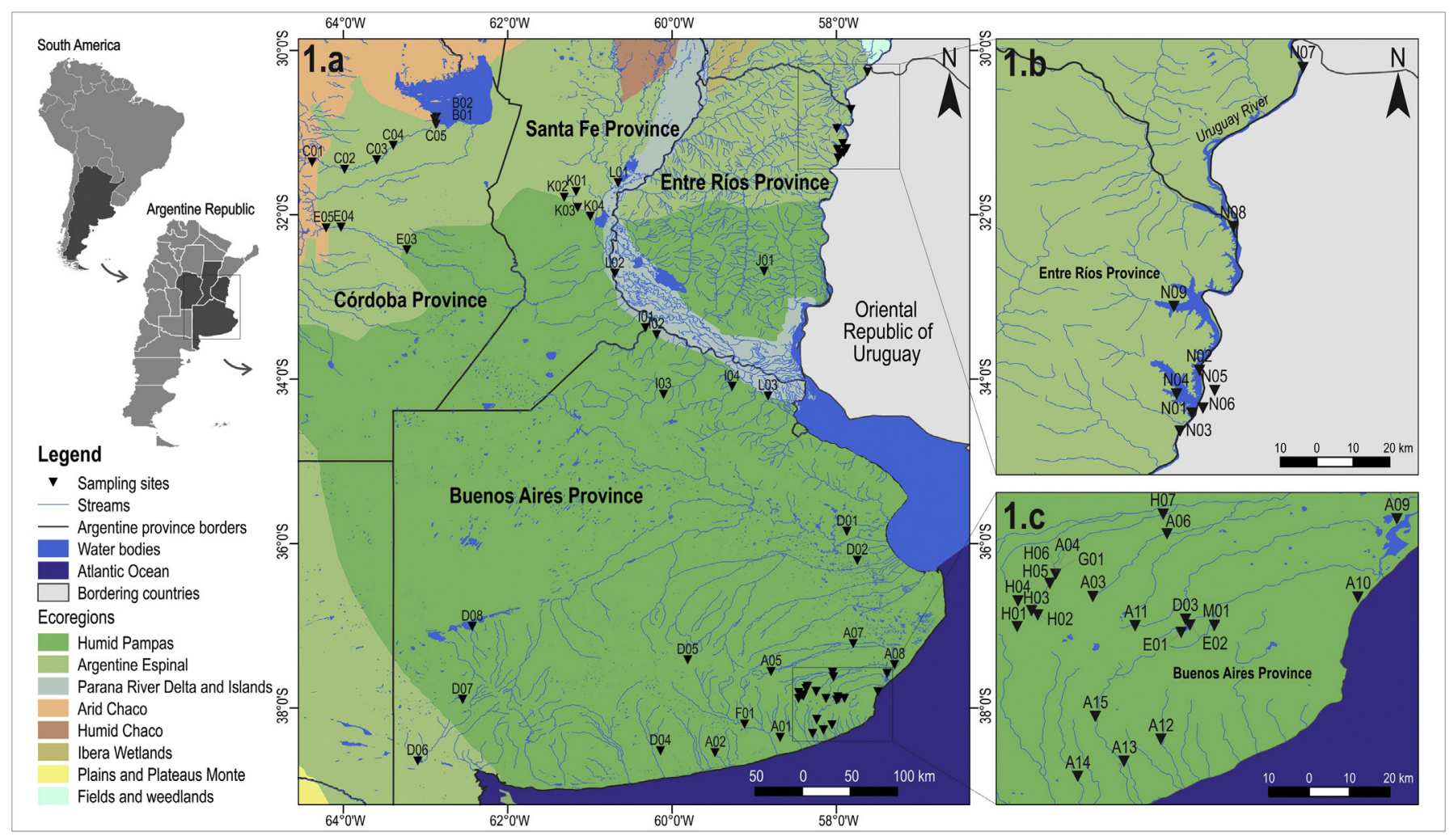

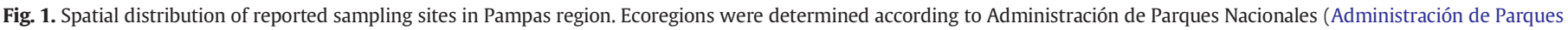
Nacionales (APN), 2019). Geo-localization of each reported site is available in a .kmz file in Supplemental Data 2.

namely the herbicides acetochlor, atrazine, imazapic and metolachlor, the fungicides carbendazim and triadimefon, and the insecticide fenitrothion. None of these products banned in Argentina are approved for use in the EU (Table 1).

At national level the use of herbicides reaches the $87 \%$ of the total amount of CUPs applied, while the fungicides and insecticides represent $4 \%$ each (CASAFE, 2017). This explains the prevalence of herbicides in monitoring studies, given their wide use in extensive agriculture in the Pampas region; the most used chemicals within this group are glyphosate and atrazine (Leguizamón, 2014). This widespread use has led to finding them not only in the water column of freshwater ecosystems, but also in soils, sediments, groundwater and even in rainfall (Aparicio et al., 2013; Alonso et al., 2018; Okada et al., 2018).

No clear trend for targeted toxicity to a specific group of organisms was observed regarding CC used for setting the corresponding PNEC for each pesticide: while $41 \%$ of used CC corresponds to fish toxicity endpoints, $32 \%$ are related to aquatic invertebrates and $27 \%$ to algae (Table 2, Supplemental Data 1). In this sense, Carazo-Rojas et al. (2018) reported that pesticides mixtures found in streams of a tropical agroecosystem in Costa Rica were most hazardous for algae than fish and aquatic invertebrates. This difference on sensitivity of taxonomic

Table 2

Number of sites per risk level, according to the sum of risk quotients for current use pesticides $\left(\Sigma R Q_{\text {cups }}\right)$ or for total pesticides $\left(\Sigma R Q_{\text {total }}\right)$. The calculated $\Sigma R Q_{\text {site }}$ were classified into five risk levels: very high risk $\left(\Sigma \mathrm{RQ}_{\text {site }} \geq 10\right)$, high risk $\left(1<\Sigma \mathrm{RQ}_{\text {site }}<10\right)$, medium $\operatorname{risk}\left(0.1<\Sigma \mathrm{RQ}_{\text {site }}<1\right)$, low risk $\left(0.01<\Sigma \mathrm{RQ}_{\text {site }}<0.1\right)$ and negligible risk $\left(0.001<\Sigma \mathrm{RQ}_{\text {site }}<\right.$ 00.1; Sanchez-Bayo et al., 2002).

\begin{tabular}{lcc}
\hline Risk level & $\Sigma R_{\text {CuPs }}\left(n^{\circ}\right.$ of sites $)$ & $\Sigma R_{\text {total }}\left(n^{\circ}\right.$ of sites $)$ \\
\hline Very high risk & 13 & 22 \\
High risk & 6 & 5 \\
Medium risk & 6 & 5 \\
Low risk & 12 & 8 \\
Negligible risk & 29 & 25 \\
\hline
\end{tabular}

groups probably could be related to the composition of the found pesticides mixtures (which depends on the adjacent land uses and transport mechanisms that deliver pesticides into aquatic habitats) and the particular toxicity of these chemicals.

The mean (range) of obtained values for $\Sigma R_{\text {cups }}$ (Table 1 ) was 20 (0-817) and for $\Sigma R Q_{\text {total }}$ (Table 1) was 59,015 (0.0005-1,073,435), suggesting a remarkable difference between CUPs and legacy pesticides toxicity. Moreover, high and very high risk $\Sigma R_{Q_{C u p s}}>1$ were observed in $29 \%$ of the sites, while $\Sigma R Q_{\text {total }}>1$ was observed in $41 \%$ of the sites (Table 2). The range of $\Sigma R Q_{\text {cups }}$ for the Pampas region reports is consistent with a study of organophosphorus pesticides in Japanese rivers which employed the same calculation approach, reporting RQs in the range of 0.006 to 257.7 (Derbalah et al., 2018). It is noteworthy that some active ingredients which are approved for their use in Argentina but banned in EU showed high contribution to $\Sigma R_{\text {RuPs }}$ where detected, e.g. acetochlor, carbendazim and fenitrothion, which reach 73, 95 and $99 \%$ of $\Sigma R Q_{\text {CuPs }}$ in some points (for a complete description of pesticides contributions see Table 3 in the Supplemental Data 1).

The spatial distribution of sites indicates higher risk in the North (Córdoba, Santa Fe and Entre Rios provinces) than in the South (Buenos Aires province, Fig. 2). This spatial trend is probably related to differential agriculture production, given that most land is used for soybean and corn plantations resistant to glyphosate in the North of the Pampas region, while in the South there is a mixed land-use, with intensive and extensive agriculture and cattle raising activity (Secretaría de Agroindustria de Argentina, 2019). However, it is noteworthy that where there was high or very high risk, the different classes of pesticides analyzed (fungicides, insecticides and herbicides) were the main contributors depending on the site (Table 3, Supplemental Data 1). While in La Brava lake (points E01 and E02) in the South of Buenos Aires province the major proportion of risk was given by the fungicide carbendazim, in the North of this province the concentrations of the herbicide glyphosate led to a $\Sigma R Q_{C u P s} \geq 1$. Moreover, in the Suquía River (Córdoba province, points C01, C02, C03, C04 and C05) the 

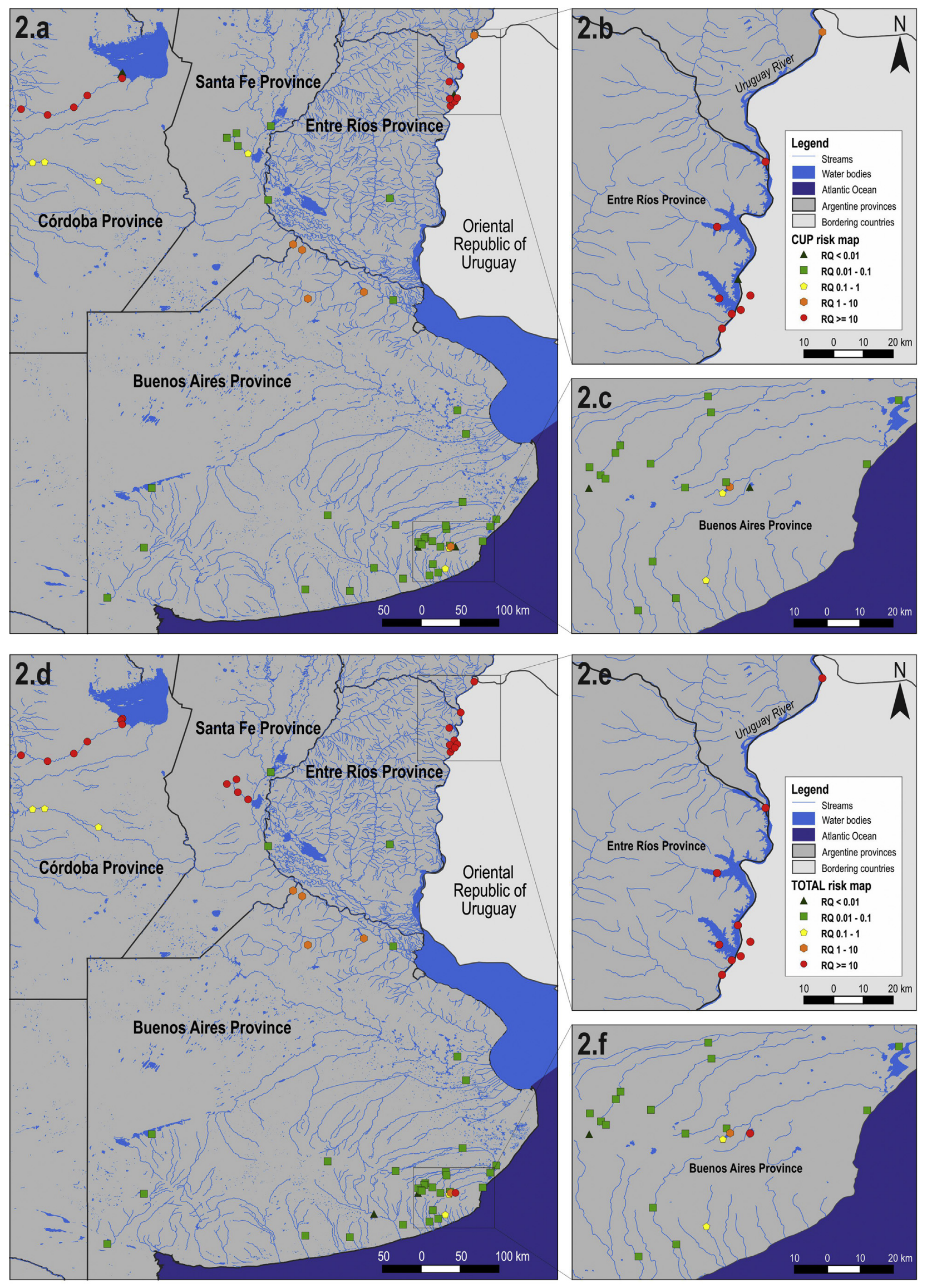
major contributor was the insecticide cypermethrin, while in the Uruguay River the organophosphorus insecticides (fenitrothion, malathion and chlorpyrifos) and the fungicides imazalil and trifloxystrobin increased the risk in greater proportion.

The legacy chemicals were $\geq 94 \%$ of $\Sigma R Q_{\text {total }}$ in all the samples where the chemical has been observed (Table 1). This is consistent with Rasmussen et al. (2015), who suggest that legacy pesticides are overlooked as highly significant contributors in current risk assessments. Endosulfan and other organochlorine pesticides (the metabolite endosulfan sulfate and endrin) increased greatly to $\Sigma R Q_{\text {total }}$. The relevance of endosulfan has been reported recently by Kapsi et al. (2019), who observed that this pesticide increased greatly the RQs in the Louros river (Greece), mainly because of its high toxicity for fishes (NOEC $96 \mathrm{~h}$ $0.1 \mathrm{ng} / \mathrm{L}$ ). However, other organochlorines, such as endrin and dieldrin have been recently reported in Ghana (Affum et al., 2018) and their concentrations did not contribute as much to calculated risks as some CUPs (e.g. cypermethryn). However, not only organochlorine pesticides influenced the increase of $\Sigma R Q_{\text {total }}$. In the present study, quantification of both banned (diazinon) and approved (malathion and fenitrothion) organophosphorus pesticides in Argentina contributed to the $\Sigma R_{\text {CuPs }}$ and the $\Sigma R Q_{\text {total }}$ (Table 3, Supplemental Data 1). Concordantly, Ccanccapa et al. (2016) noted that organophosphorus pesticides concentrations present in Ebro River (Spain) represented a high risk for algae, aquatic invertebrates and fish.

The presence of banned pesticides in freshwater ecosystems may be related to several processes. Firstly, the physicochemical characteristics of legacy pesticides (e.g. persistence, stability, lipophilicity) allowed them a long-term persistence in soils such that after several runoff processes could be transported to the aquatic ecosystems (Gonzalez et al., 2012). Second, partitioning between bottom sediments of water bodies and water could be altered by re-suspension of contaminated sediments (Quesada et al., 2014). Finally, it is not possible to discard a recent input of these chemicals, including illegal application or even an indirect release as byproduct of impurities of approved pesticides (for a comprehensive description of possible sources of legacy compounds see McKnight et al., 2015).

During the past few years, ERA has incorporated new approaches and tools, from ecosystem services endpoints (Munns Jr et al., 2016) to in silico methodologies including QSAR-based (Raitano et al., 2018) and toxicokinetic-toxicodynamic models (Jager and Ashauer, 2018). However, given the survey of pesticides reports done for this study, there is a clear need to develop a standardized and comprehensive monitoring program for the Pampas region. This fact arises from the dissimilarities in the pesticides which were investigated by different authors in cited reports. This harmonization should include not only the most applied pesticides, but also those which had evidenced to be most hazardous for aquatic biota. Finally, it is noteworthy that despite the lower toxicity of most of CUPs in comparison with legacy compounds, CUPs were not available for their use (and consequently present in the environment) for as long as legacy chemicals, and further data of fate and toxicity of the latest released molecules would be necessary for ERA.

\section{Conclusion}

This is the first study that attempts to develop an ERA of pesticides in aquatic ecosystems of the Pampas region. Employing the RQ approach for pesticides mixtures, our results highlight the contribution of different CUPs in risk for aquatic biota as well as the importance of taking into account legacy pesticides contribution in risk assessment. Further studies should include models which focus on the assessment of synergistic/antagonistic pesticides effects not addressed in the present study and higher tier approaches for those sites which unacceptable risks were expected, to confirm risks and take decisions.

\section{Acknowledgments}

This work was supported by Agencia Nacional de Promoción Científica y Tecnológica (FONCyT PICT 2017-0980) and Universidad Nacional de Mar del Plata (UNMDP EXA codes 899/18 and 900/18). Thanks to Daniela Garanzini for the picture used in the graphical abstract.

\section{Appendix A. Supplementary data}

Supplementary data associated with this article can be found in the online version, at doi:https://doi.org/10.1016/j.scitotenv.2019.07.044. These data include the Google Earth .kmz file with the Geolocalization of each reported site for this article.

\section{References}

Administración de Parques Nacionales (APN), 2019. https://sib.gob.ar/eco-regiones.

Affum, A.O., Acquaah, S.O., Osae, S.D., Kwaansa-Ansah, E.E., 2018. Distribution and risk assessment of banned and other current-use pesticides in surface and groundwaters consumed in an agricultural catchment dominated by cocoa crops in the Ankobra Basin, Ghana. Sci. Total Environ. 633, 630-640.

Alonso, L.L., Demetrio, P.M., Etchegoyen, M.A., Marino, D.J., 2018. Glyphosate and atrazine in rainfall and soils in agroproductive areas of the pampas region in Argentina. Sci. Total Environ. 645, 89-96.

Altenburger, R., Boedeker, W., Faust, M., Grimme, L.H., 1996. Regulations for combined effects of pollutants: consequences from risk assessment in aquatic toxicology. Food Chem. Toxicol. 34, 1155-1157.

Anderson, B.S., Phillips, B.M., Voorhees, J.P., Deng, X., Geraci, J., Worcester, K., Tjeerdema, R.S., 2018. Changing patterns in water toxicity associated with current use pesticides in three California agriculture regions. Integr. Environ. Assess. Manag 14, 270-281.

Aparicio, V.C., De Gerónimo, E., Marino, D., Primost, J., Carriquiriborde, P., Costa, J.L., 2013. Environmental fate of glyphosate and aminomethylphosphonic acid in surface waters and soil of agricultural basins. Chemosphere 93 (9), 1866-1873.

Arancibia, F., 2013. Challenging the bioeconomy: the dynamics of collective action in Argentina. Technol. Soc. 35, 79-92.

Backhaus, T., Faust, M., 2012. Predictive environmental risk assessment of chemical mixtures: a conceptual framework. Environ. Sci. Technol. 46, 2564-2573.

Ballesteros, M.L., Miglioranza, K.S.B., Gonzalez, M., Fillmann, G., Wunderlin, D.A., Bistoni, M.A., 2014. Multimatrix measurement of persistent organic pollutants in Mar Chiquita, a continental saline shallow lake. Sci. Total Environ. 490, 73-80.

Bonansea, R., Filippi, I., Wunderlin, D., Marino, D. Amé, M., 2018. The fate of glyphosate and AMPA in a freshwater endorheic basin: an ecotoxicological risk assessment. Toxics 6 (1), 3.

Bonansea, R.I., Amé, M.V., Wunderlin, D.A., 2013. Determination of priority pesticides in water samples combining SPE and SPME coupled to GC-MS. a case study: Suquía River basin (Argentina). Chemosphere 90 (6), 1860-1869.

Bundschuh, M., Goedkoop, W., Kreuger, J., 2014. Evaluation of pesticide monitoring strategies in agricultural streams based on the toxic-unit concept-experiences from longterm measurements. Sci. Total Environ. 484, 84-91.

Bussian, B.M., Pandelova, M., Lehnik-Habrink, P., Aichner, B., Henkelmann, B., Schramm, K.-W., 2015. Persistent endosulfan sulfate is found with highest abundance among endosulfan I, II, and sulfate in German forest soils. Environ. Pollut. 206, 661-666.

Carazo-Rojas, E., Pérez-Rojas, G., Pérez-Villanueva, M., Chinchilla-Soto, C., Chin-Pampillo, J.S., Aguilar-Mora, P., Alpízar-Marín, M., Masís-Mora, M., Rodríguez-Rodríguez, C.E., Vryzas, Z 2018. Pesticide monitoring and ecotoxicological risk assessment in surface water bodies and sediments of a tropical agro-ecosystem. Environ. Pollut. 241, 800-809.

CASAFE, 2017. Guía de Productos Fitosanitarios 2017/2019. 18th edition. Cámara de Sanidad Agropecuaria y Fertilizantes, Argentina.

Castro-Berman, M., Marino, D.J.G., Quiroga, M.V., Zagarese, H., 2018. Occurrence and levels of glyphosate and AMPA in shallow lakes from the Pampean and Patagonian regions of Argentina. Chemosphere 200, 513-522.

Ccanccapa, A., Masiá, A., Navarro-Ortega, A., Picó, Y., Barceló, D., 2016. Pesticides in the Ebro River basin: occurrence and risk assessment. Environ. Pollut. 211, 414-424.

Cedergreen, N., 2014. Quantifying synergy: a systematic review of mixture toxicity studies within environmental toxicology. PLoS One 9, e96580.

Connell, D., 2005. Basic Concepts of Environmental Chemistry. Second edition. CRC Press (480 pp).

Corcoran, S., Menone, M.L, Amé, M.V., Lukaszewicz, G., Garanzini, D.S., Iturburu, F.G., Metcalfe, C., 2017. Detection of current- use pesticides in Argentinian surface waters

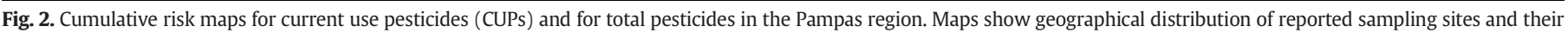

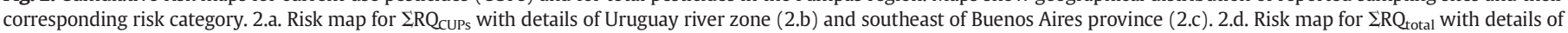
Uruguay river zone (2.e) and southeast of Buenos Aires province (2.f). Geo-localization of each reported site is available in a .kmz file in Supplemental Data 2. 
using polar organic chemical integrative samplers (POCIS). SETAC Latin America 12th Biennial Meeting Abstract Book.

De Gerónimo, E., Aparicio, V.C., Bárbaro, S., Portocarrero, R., Jaime, S., Costa, J.L., 2014. Presence of pesticides in surface water from four sub-basins in Argentina. Chemosphere 107, 423-431.

Deneer, J.W., 2000. Toxicity of mixtures of pesticides in aquatic systems. Pest Manag. Sci. 56, 516-520.

Derbalah, A., Chidya, R., Jadoon, W., Sakugawa, H., 2018. Temporal trends in organophosphorus pesticides use and concentrations in river water in Japan, and risk assessmentz. J. Environ. Sci. 79, 135-152.

Etchegoyen, M.A., Ronco, A.E., Almada, P., Abelando, M., Marino, D.J., 2017. Occurrence and fate of pesticides in the Argentine stretch of the Paraguay-Paraná basin. Environ. Monit. Assess. 189 (2), 63.

van Gestel, C.A.M., Jonker, M.J., Kammenga, J.E., Laskowski, R., Svendsen, C., 2011. Mixture Toxicity: Linking Approaches from Ecological and Human Toxicology. CRC Press (320 pp).

Gonzalez, M., Miglioranza, K.S., Shimabukuro, V.M., Londoño, O.M.Q., Martinez, D.E., Aizpún, J.E., Moreno, V.J., 2012. Surface and groundwater pollution by organochlorine compounds in a typical soybean system from the south Pampa, Argentina. Environ. Earth Sci. 65 (2), 481-491.

Gustavsson, M., Kreuger, J., Bundschuh, M., Backhaus, T., 2017. Pesticide mixtures in the Swedish streams: environmental risks, contributions of individual compounds and consequences of single-substance oriented risk mitigation. Sci. Total Environ. 598, 973-983.

Jager, T., Ashauer, R., 2018. How to evaluate the quality of toxicokinetic-Toxicodynamic models in the context of environmental risk assessment. Integr. Environ. Assess. Manag. 14 (5), 604-614.

Kapsi, M., Tsoutsi, C., Paschalidou, A., Albanis, T., 2019. Environmental monitoring and risk assessment of pesticide residues in surface waters of the Louros River (NW Greece). Sci. Total Environ. 650, 2188-2198.

Lahr, J., Kooistra, L., 2010. Environmental risk mapping of pollutants: state of the art and communication aspects. Sci. Total Environ. 408, 3899-3907.

Leguizamón, A., 2014. Modifying Argentina: GM soy and socio-environmental change. Geoforum 53, 149-160.

Lewis, K.A., Tzilivakis, J., Warner, D.J., Green, A., 2016. An international database for pesticide risk assessments and management. Human and Ecological Risk Assessment: An International Journal 22, 1050-1064.

Liess, M., Foit, K., Knillmann, S., Schäfer, R.B., Liess, H.-D., 2016. Predicting the synergy of multiple stress effects. Sci. Rep. 6, 32965

Lupi, L., Bedmar, F., Wunderlin, D.A., Miglioranza, K.S.B., 2016. Organochlorine pesticides in agricultural soils and associated biota. Environ. Earth Sci. 75 (519), 1-11.

Lytle, J.S., Lytle, T.F., 2001. Use of plants for toxicity assessment of estuarine ecosystems. Environ. Toxicol. Chem. 20, 68-83.

McKnight, U.S., Rasmussen, J.J., Kronvang, B., Binning, P.J., Bjerg, P.L., 2015. Sources, occurrence and predicted aquatic impact of legacy and contemporary pesticides in streams. Environ. Pollut. 200, 64-76.

Munns Jr., W.R., Rea, A.W., Suter, G.W., Martin, L., Blake-Hedges, L., Crk, T., Davies, C., Ferreira, G., Jordan, S., Mahoney, M., Barron, M.G., 2016. Ecosystem services as assessment endpoints for ecological risk assessment. Integr. Environ. Assess. Manag. 12 (3), 522-528.

Okada, E., Pérez, D., De Gerónimo, E., Aparicio, V., Massone, H., Costa, J.L., 2018. Non-point source pollution of glyphosate and AMPA in a rural basin from the southeast pampas, Argentina. Environ. Sci. Pollut. Res. Int. 25, 15120-15132.

Papadakis, E.-N., Tsaboula, A., Kotopoulou, A., Kintzikoglou, K., Vryzas, Z., PapadopoulouMourkidou, E., 2015. Pesticides in the surface waters of Lake Vistonis Basin, Greece: occurrence and environmental risk assessment. Sci. Total Environ. 536, 793-802.

Pérez, D.J., Okada, E., De Gerónimo, E., Menone, M.L., Aparicio, V.C., Costa, J.L., 2017a. Spatial and temporal trends and flow dynamics of glyphosate and other pesticides within an agricultural watershed in Argentina. Environ. Toxicol. Chem. 36 (12), 3206-3216.
Pérez, D.J., Okada, E., Menone, M.L., Costa, J.L., 2017b. Can an aquatic macrophyte bioaccumulate glyphosate? Development of a new method of glyphosate extraction in Ludwigia peploides and watershed scale validation. Chemosphere 185, 975-982.

Peruzzo, P.J., Porta, A.A., Ronco, A.E., 2008. Levels of glyphosate in surface waters, sediments and soils associated with direct sowing soybean cultivation in north pampasic region of Argentina. Environ. Pollut. 156 (1), 61-66.

Primost, J.E., Marino, D.J., Aparicio, V.C., Costa, J.L., Carriquiriborde, P., 2017. Glyphosate and AMPA, "pseudo-persistent" pollutants under real-world agricultural management practices in the Mesopotamic Pampas agroecosystem, Argentina. Environ. Pollut. 229, 771-779.

Quesada, S., Tena, A., Guillén, D., Ginebreda, A., Vericat, D., Martínez, E., Navarro-Ortega, A., Batalla, R.J., Barceló, D., 2014. Dynamics of suspended sediment borne persistent organic pollutants in a large regulated Mediterranean river (Ebro, NE Spain). Sci. Total Environ. 473, 381-390.

Raitano, G. Goi, D. Pieri, V, Passoni, A., Mattiussi, M., Lutman, A, Romeo, I, Manganaro, A Marzo, M., Porta, N., Baderna, D., Colombo, A., Aneggi, E., Natolino, F., Lodi, M., Bagnati, R., Benfenati, E., 2018. (Eco) toxicological maps: a new risk assessment method integrating traditional and in silico tools and its application in the Ledra River (Italy). Environ.Int. 119, 275-286.

Rasmussen, J.J., Wiberg-Larsen, P., Baattrup-Pedersen, A., Cedergreen, N., McKnight, U.S. Kreuger, J., Jacobsen, D., Kristensen, E.A., Friberg, N., 2015. The legacy of pesticide pollution: an overlooked factor in current risk assessments of freshwater systems. Water Res. 84, 25-32.

Regaldo, L., Gutierrez, M.F., Reno, U., Fernández, V., Gervasio, S., Repetti, M.R., Gagneten, A.M., 2018. Water and sediment quality assessment in the Colastiné-Corralito stream system (Santa Fe, Argentina): impact of industry and agriculture on aquatic ecosystems. Environ. Sci. Pollut. R. 25 (7), 6951-6968.

Ronco, A.E., Marino, D.J.G., Abelando, M., Almada, P., Apartin, C.D., 2016. Water quality of the main tributaries of the Paraná Basin: glyphosate and AMPA in surface water and bottom sediments. Environ. Monit. Assess. 188 (8), 458.

Sanchez-Bayo, F., Baskaran, S., Kennedy, I.R., 2002. Ecological relative risk (EcoRR): another approach for risk assessment of pesticides in agriculture. Agric. Ecosyst. Environ. 91, 37-57.

Secretaría de Agroindustria de Argentina, 2019. Visor de Infraestructura de Datos Espaciales (consulted February 2019). Available in. https://geoportal.agroindustria. gob.ar/visor/.

Servicio Nacional de Sanidad y Calidad Agroalimentaria (SENASA), 2011. Resolución 511/ 2011. Available in:. https://www.senasa.gob.ar/.

Silva- Barni, M.F., Ondarza, P.M., Gonzalez, M., Da Cuña, R., Meijide, F., Grosman, F. Sanzano, P., Lo Nostro, F.L., Miglioranza, K.S.B., 2016. Persistent organic pollutants (POPs) in fish with different feeding habits inhabiting a shallow lake ecosystem. Sci. Total Environ. 550, 900-909.

Swedish Chemicals Agency, 2014. Update to include Endosulfan in the Swedish National Implementation Plan for the Stockholm Convention on Persistent Organic Pollutants. Available in:. https://www.kemi.se/.

US-EPA, 2018. US-EPA ECOTOX database, USA. https://cfpub.epa.gov/ecotox/.

Vašičková, J., Hvězdová, M., Kosubová, P., Hofman, J., 2019. Ecological risk assessment of pesticide residues in arable soils of the Czech Republic. Chemosphere 216, 479-487.

Vryzas, Z., Alexoudis, C., Vassiliou, G., Galanis, K., Papadopoulou-Mourkidou, E., 2011. Determination and aquatic risk assessment of pesticide residues in riparian drainage canals in northeastern Greece. Ecotoxicol. Environ. Saf. 74, 174-181.

Williman, C., Munitz, M.S., Montti, M.I.T., Medina, M.B., Navarro, A.F., Ronco, A.E., 2017 Pesticide survey in water and suspended solids from the Uruguay River Basin, Argentina. Environ. Monit. Assess. 189, 259. 